\title{
Integrating strategic planning values into urban master planning process in Vietnam
}

\author{
Van Phuc $\mathrm{Ma}^{1}$ and Trung Vinh Tran ${ }^{1, *}$ \\ ${ }^{1}$ University of Architecture Ho Chi Minh City, 196 Pasteur str., Ho Chi Minh City, 625000, Vietnam
}

\begin{abstract}
Today, Urban Planning in Vietnam faces a lot of problems due to the paradox between traditional master planning systems and modern context of rapid transformation. Alternatives are practiced in some cities, especially in the context of international integration. Various methods and cooperative projects have attempted to subvert the strict master-planning approach with high levels of centralization and reliance upon planning by command and control. However, despite many efforts, it seems impossible to completely replace current planning system by another advance method, which has no attachments with its developed context. The paper studies and schematizes the complexity of master planning process in Vietnam, which is regulated by various legal documentaries. On the other hand, it simultaneously studies strategic planning method and selectively chooses valuable features which fits local context. By confronting and integrating them with each other, the paper aims to introduce an advance master planning process that adaptive and flexible to modern challenges.
\end{abstract}

\section{Introduction}

Vietnam is in a rapid urbanization process. Going hand-in-hand with it, urban planning has made positive changes but still remains relatively limited, not adapted to challenges and the rapid changes in the market economy. Moreover, in order to successfully deal with the international integration process, which is happening now in different scale and scope, some additions of more adaptive method should be added to the current urban planning system.

Recently, to restrict deficiencies of the traditional urban planning method, new approaches in urban planning have been researched and applied by Vietnam Government Agencies. However, the application of methods in urban planning has not achieved the desired results; the new methods have not yet been institutionalized and matched with the existing urban context of Vietnam [1].

Strategic planning, which is a continuous dynamic method and able to adapt with many circumstances, has been applied spaciously and operatively in many developed countries. The integration between traditional urban planning method and values of Strategic Planning approach will complement each other and make urban planning system more complete, flexible, feasible and responsive to challenges of rapid urbanization process in Vietnam, especially in context of international integration. [1]

\footnotetext{
${ }^{*}$ Corresponding author: trantrungvinh.ud@gmail.com
} 


\section{Literature review}

\subsection{Overview of Vietnamese planning system}

Vietnam planning system is simultaneously under control of various types of planning, including: overall planning of socio-economic development at all levels with the management level operating under the Ministry of Planning and Investment; physical planning at all levels under control of the Ministry of Construction; land use planning follows the Ministry of Natural Resources and Environment; planning the specialized fields of the specialized Ministries (Figure 1) [2].

\section{PLANNING SYSTEM IN VIETNAM}

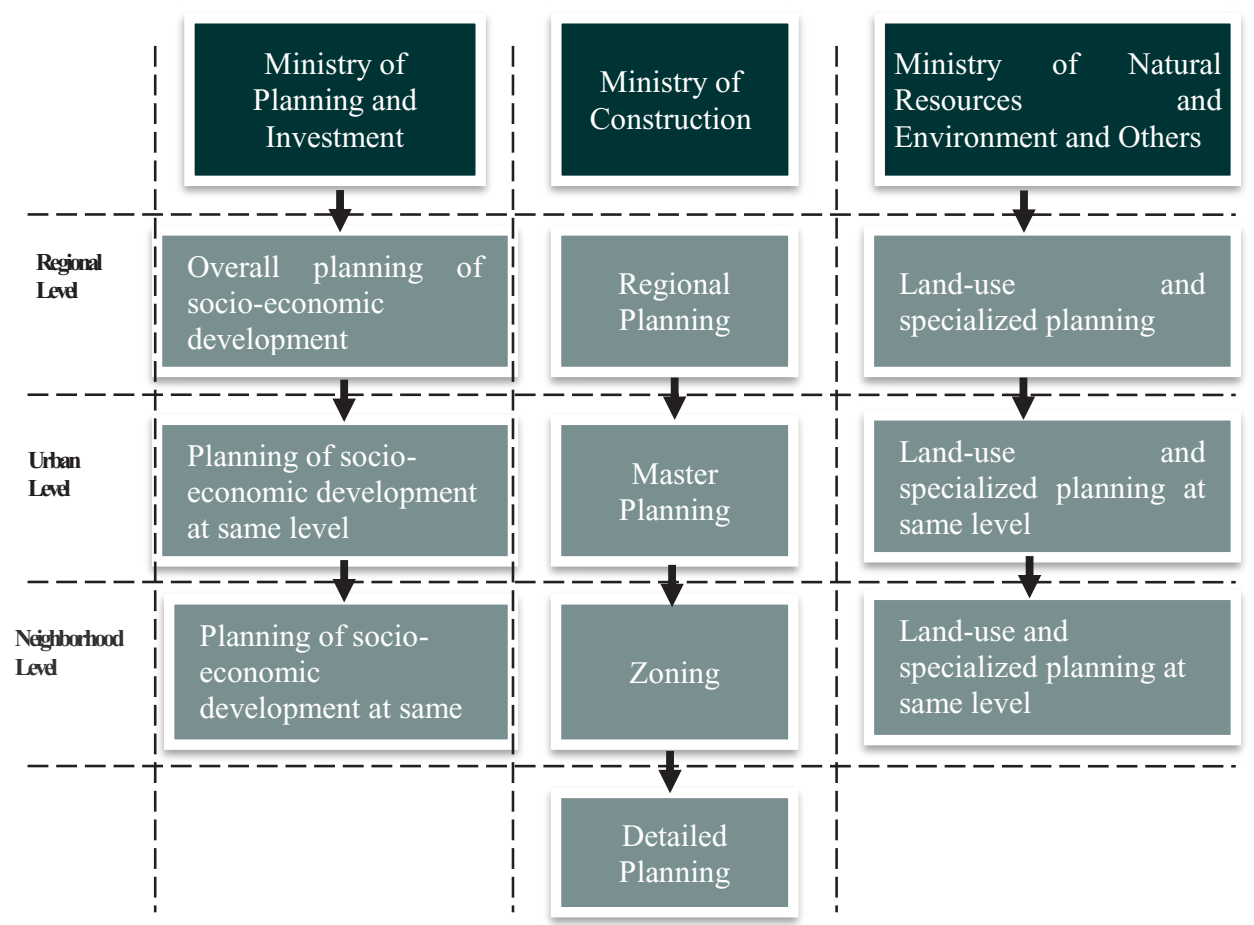

Fig. 1. Planning system in Vietnam (Source: Authors).

The common principle is to consolidate the coherence between different planning types, as well as the inheritance of different stages within one type. Nevertheless, contents and procedure reveal a lot of monodisciplinary and do not meet their tight linkage because each planning is implemented under their own legal base, frequently overlapping each other in both contents and implementation process.

\subsection{Evolution of Vietnamese urban planning system (1986-2015)}

In recent years, Vietnamese urban planning work has changed sharply in both volume and quality. The authorities have consistently improved planning processes, policies, planning frameworks, decrees, decisions, circulars, and law on urban planning was also announced for the work of construction and urban development. 
From the decision 322/1993-QD/DT issued in 1993 and Decree 91- CP dated on $08 / 17 / 1994$ by the Government, urban planning still has many shortcomings, had been replaced by Decree 08/2005 ND-CP had yet to adapt to the evolution of the urban complex. Urban planning law dated 17/06/2009, Decree 37/2010/ND-CP dated 07/04/2010 on the formulation, appraisal, approval and management of the urban planning, had continued to improve the urban planning work [2-4].

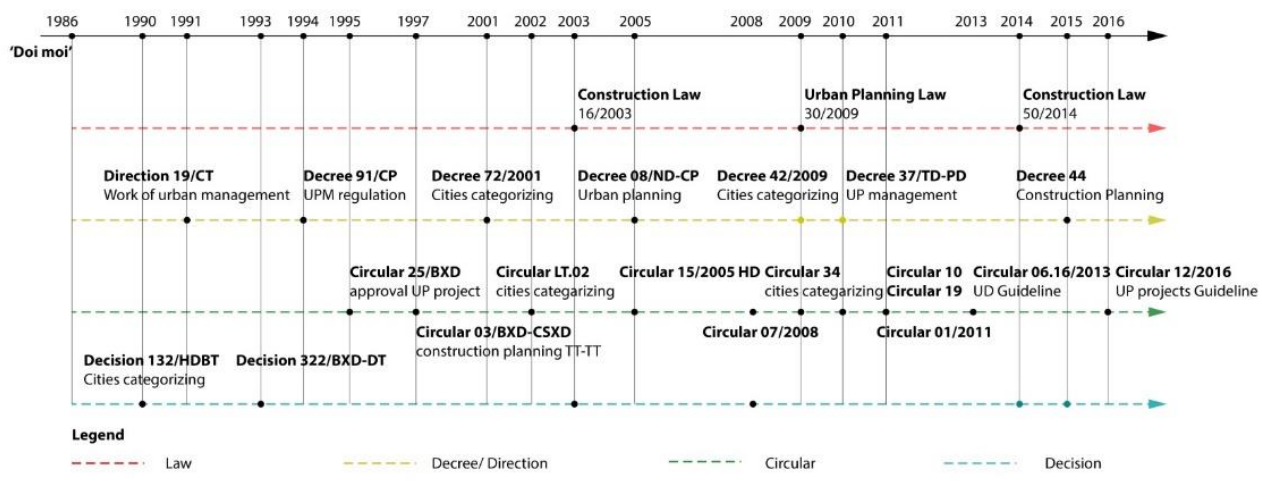

Fig. 2. Schematizing fundamental legal bases of urban planning and urban management (Source:

Authors, 2016).

\subsection{Contents and process of master planning in Vietnam}

According to Urban Planning Law issued in 2009, master planning projects are made in 4 groups: cities under central authority; cities of province; towns, and new cities. Nevertheless, all of these groups are basically implemented in 4 stages: (1) problem identification, (2) analysis, evaluation, vision, and targets building, (3) strategy selection, action plans building (decision making), (4) implementations and reviews [2].

Although the process is divided in stages under precise schedule, the progress rarely done on time. Because urban projects management is made and appraised under a mechanism with rigid procedure, which follows traditional master planning based on intricate regulations and standards and capacity of experts, managers, and politicians. It is inflexible and unable to adapt with the urban complexity. Therefore, urban planning process still remains utmost limited in implementation which is necessary to have addition, melioration, and improvement to adapt with the development context of Vietnam and international integration process. 


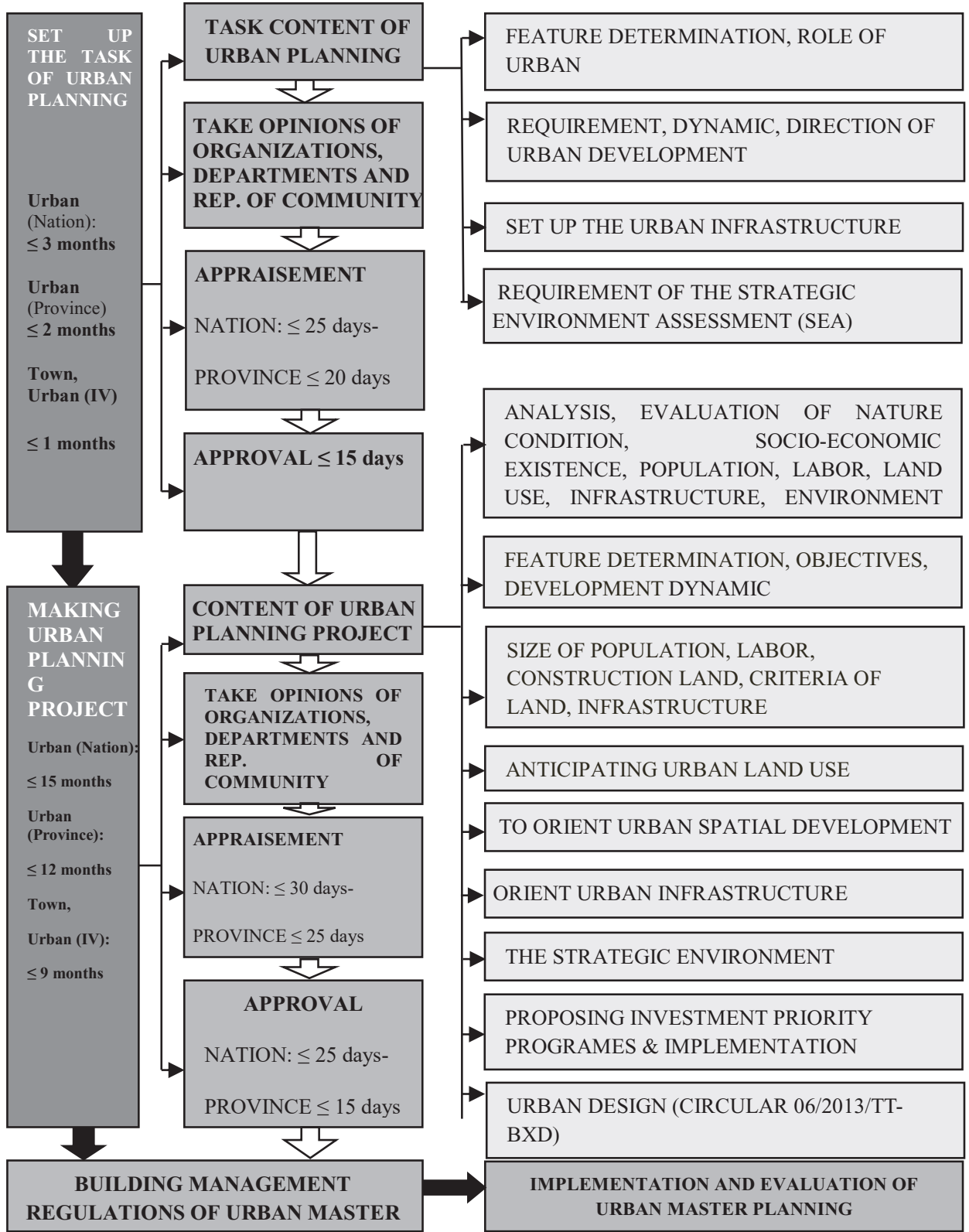

Fig. 3. Chart of urban master planning process from Decree 37/2010 NĐ-CP Dated 07/04/2010 (Author, 2015).

\subsection{An overview of strategic planning}

The term 'strategy' was first used in the military, then from the 1950's-1960's strategic concept was transferred from military - political field to socio-economic one, and in the late 1980s, strategic planning developed in the urban field. Recently, strategic planning has been applied broadly, not only in developed countries but also in developing and underdeveloped one as a tool to mobilize and develop local economy, principally throughout the strategic planning program held by UN Habitat in many different urban contexts worldwide. [1] 


\subsection{Main features of strategic planning}

Main features of strategic planning are: Firstly, it provides a result-oriented framework defining the vision and the long-term strategy with realism. Secondly, strategic planning has flexible ability depends on context, using the method of analysis has criticized the system's environment to identify strengths and weaknesses, opportunities and threats. Third, it has the capacity to mobilize, not only require multidisciplinary collaboration but also invites all the partners to participate together into the planning from both the private and public sectors. Last but not least, the process of strategic planning is a continuous process which is "a framework that includes recommendations for the medium and long term action and a mechanism for the short term detailed planning. the typical strategic planning process including 4 stages (figure 4): (1) problem identification, (2) analysis, evaluation, building the vision, targets, (3) strategy selection, build action plans, (4) implementations, reviews [1].

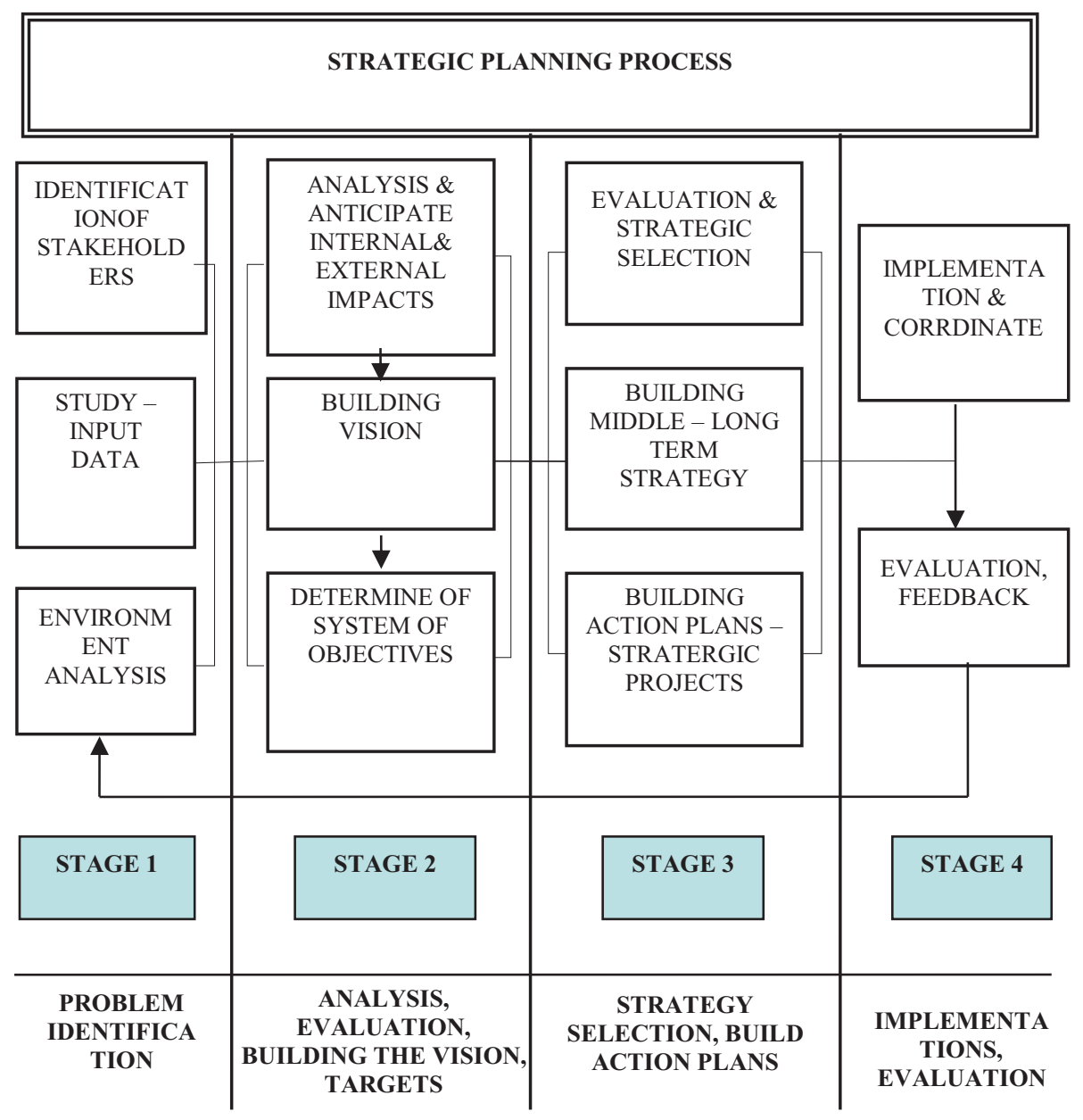

Fig. 4. Typical strategic planning diagram (Source: Authors, 2015).

\section{Values of strategic planning}

Throughout the general content of urban planning in Vietnam and strategic planning, as well as the idea collection from experts in construction and urban planning field, authors 
selectively choose values of strategic planning appropriate with Vietnam urban development context. They are: systematic and continuous planning process, building of the vision and action plan, consultation and participation in the planning process and monitoring and assessment in the planning process. [1]

On the basis of analyzing and systematizing the content and process of Strategic Planning from Do Phu Hung in 2004 about the contents of action-oriented, master planning method is replaced by sequences of actions [5]. Strategic Planning Frame from Civicus comprising of fundamental phase which is building a vision, establishing targets, strategic projects and action plan [6]. Document of local economic development through strategic planning implemented by the UN-HABITAT provide a procedure 10-steps strategic process, correspondence with 4 phases of local economic development [7-11]. Strategic structure planning defined by Jef van den Broeck provides other approaches of strategic planning, which could be considered as a dynamic process, continuously and openly, of urban planning or broader as socialism process [12]. CDS, proposed by Sustainable Development Institute of Sydney University of Technology, is an 8-components process: (1) design process CDS, (2) site analysis, (3) vision, target and strategy, (4) action plan, (5) implementation and integration, (6) consultation and participation, (7) environmental strategic assessment, (8) monitoring and evaluation [13].

\subsection{Strategic planning study in Vietnam}

In the international integration process, especially after 1986 of 'Doimoi'(Vietnam's perestroika), the country operates under Socialist economic market-orientation, cities in Vietnam face many challenges in eco-social and environment. The field of urban planning and management, step-by-step, accost and import and apply many advanced methods, tools throughout the transferring and integrating values into Vietnam's legal system. Among those, strategic planning has been studied and proposed to apply in different levels by many authors.

Author Nguyen Dang Son, with the integration criteria of different planning into strategic integrated planning, has published the works of Strategic Planning have provided more meaningful content in terms of the reasoning are scholarly in the management, construction and urban development [14-16]. Author Vo Kim Cuong and his team with the proposed CDS process is the process the combined municipality consisting of eight key steps to integrate social and economic planning built to avoid the overlap and duplication by many types of planning,... are meant for the applied to the theoretical basis of the related topics of interest [17]. The guide documentation CDS in Vietnam implemented by the Sustainable Development Institute of Sydney University of Technology (2007), have provided a framework of processes according to the approach of Strategic Planning for the municipality in Vietnam [13]. Author Nguyen Ngoc Hieu has presented a number of issues about the process and the method of making urban planning. The author has confirmed that the needs of innovation from the inside out thinking how to do planning on Vietnam. Urban planning will ensure successful strategies in both the process of establishment and implementation management [18]. Author Nguyen Hong Thuc presented the integrated strategic planning and the ability to apply the planning system in Vietnam. The author identified the application of strategic planning in Vietnam is almost the only way to bring performance and feasible planning [19].

\section{Materials and methods}

The paper uses several of methods including: systemic method, expert method, analytical method, synthetic and evaluative method, comparative and inductive method. 


\section{Results}

Propose integrating strategic planning into Vietnam master planning process.

Before propose to integrating strategic planning values into Vietnam current master planning, a question rising up is to completely replace by strategic planning in which many developed countries has been successfully and effectively applied. Even though practice experience in many cases proves the sufficiency and possibilities to manipulate entirely strategic planning method, there are also numerous cities that unsuccessfully apply this theory since the beginning and need to readjust twice or even three times like the case in Havana, Cuba. Because there is no a theory or model that can be applied everywhere. In the context of rapid urbanization, the master planning system is in operation in massive scale and scope of Vietnam reality urban development. Urban planning work is already institutionalized through planning law, regulations, decrees, circulars, etc. and still ongoing. It is very difficult, if not to say impossible, to completely replace current one by another advance planning methods which have no attachments with its developed context. In our opinion, the most effective foreseen solution is step-by-step integration of valuable content of strategic planning instead of an absolute replacement.

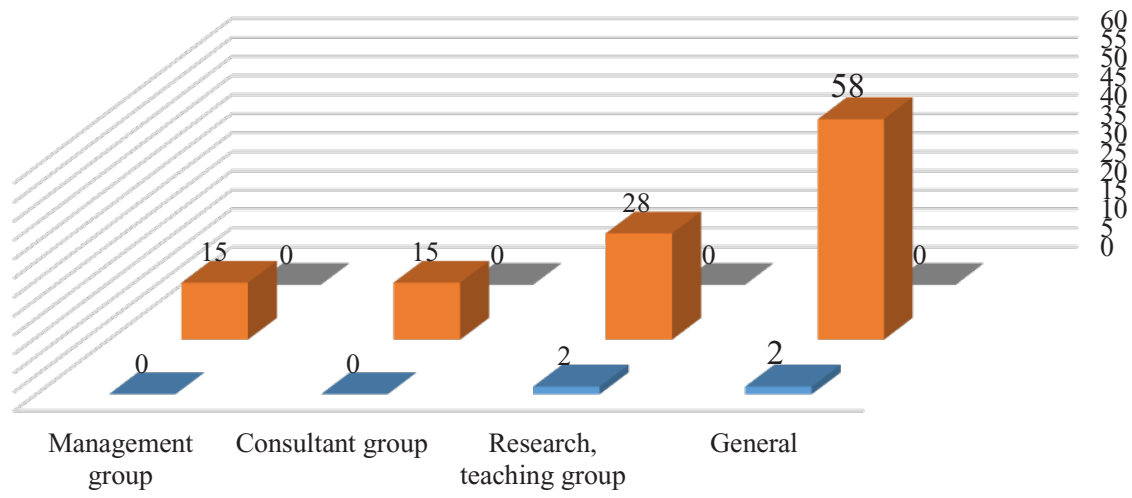

- Necessary to completely replacement

Necessary to integrate valuable contents

Other ideas

Fig. 5. Experts ideas of how to apply strategic planning theory (Source: Authors, 2016).

Throughout the analyzing the work of urban planning in Vietnam development context and international integration as well as synthesize ideas collected from 60 experts in urban planning and management field (figure 5) to come up with the perception that in recent stage and up-coming time, most appropriated solution is just only integrating strategic values instead of completely replacement.

Bases of typical Vietnam master planning and strategic planning were schematized into dual process so as to easily collating and confronting each other (figure 6). Obviously, both process has 4 main stages, deeply analyzing contents in each stages, Authors come out with the proposal for integrating strategic values into current Vietnam master planning process (figure 7). First stage: setting up mission of urban master planning, which is considered as issue identification stage, is needed to integrate the stakeholders and participation and flexible features of strategic planning. Strategic planning require high consensus of stakeholder regarding to planning arena. As such, determining stakeholder is in the first phase so that they can be involved since the beginning and during the whole procedure [20]. Second stage: setting up project of urban master planning which is divided into 2 groups: the first 
includes contents of analysis, natural condition evaluation; defining feature, objective, development dynamic and urban scale of orientation, while other contents are in the second one. The content of forming "vision" is proposed of being integrated into the first group of Vietnamese urban master planning process. The additional content of forming Vision is critical meaning and plays a very important role to link all the contents not only within urban planning process but also other planning process meanwhile vision creation require all stakeholder involving since the beginning. Vision would be defined when converging many correlative advantages and high approbation of stakeholders. Contents of action planning should be included into the second group in the stage 2 of urban master planning process, combined with proposed contents for prioritized investment programs and implement resources are able to meet the implement process with high feasibility and practicality [21, 22].

Third Stage: management regulations according to urban master planning: the mission needs to integrate with the contents of action planning so as to conjoin the implementation procedure, resources as well as stakeholders following the plan. Fourth Stage: last but not least is the implementation organization - evaluation. When planning project is qualified for promulgation and development of planning project implement work. Monitoring and evaluation is required frequent implementation in the principle of cooperation between stakeholders to consolidate the flexibility and effectively of the whole process.

After synthesize the integrating values of strategic planning into Vietnam master planning, the paper proposes a new process as in figure 7.

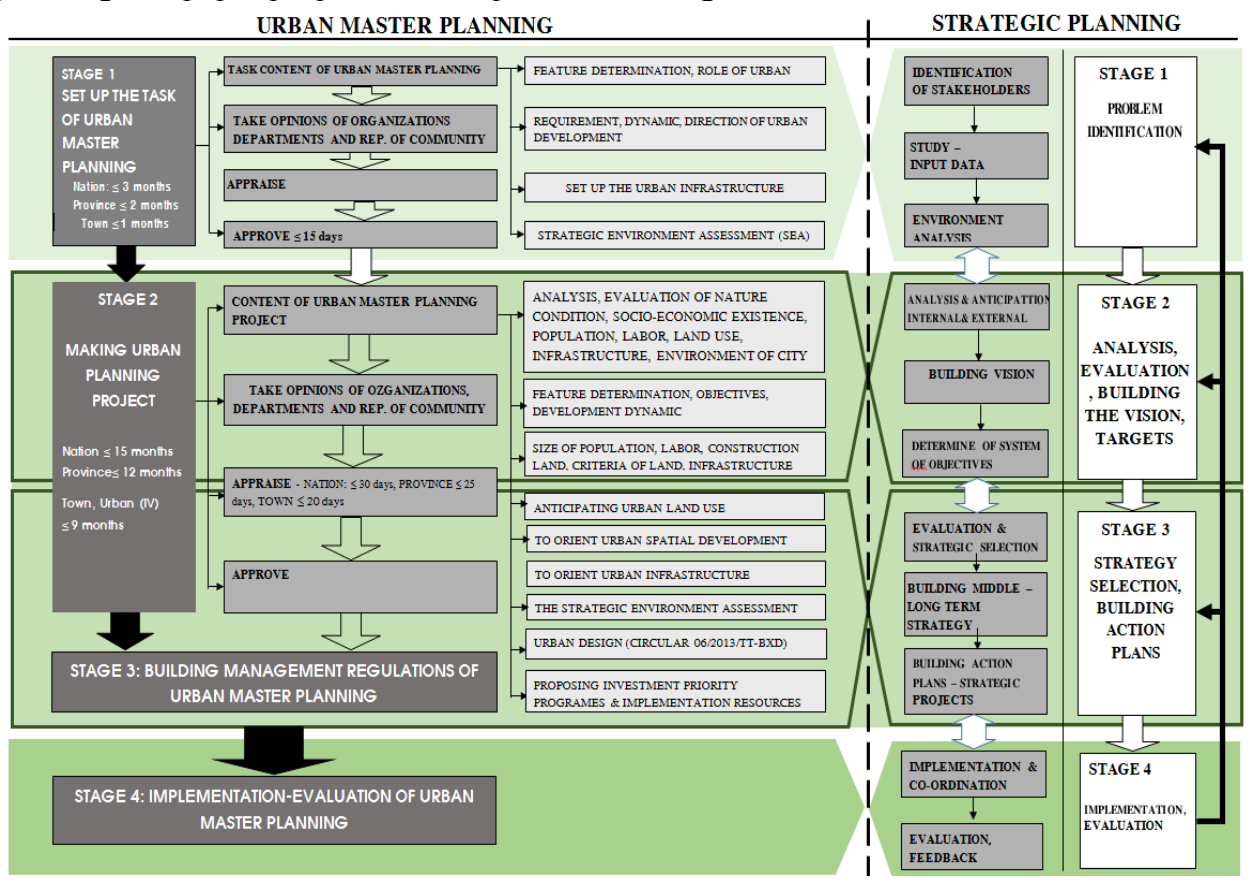

Fig. 6. Interrelation between Vietnam master planning process and strategic planning process. (Source: Authors).

In order to successfully applied, it is necessary to carefully analyzing local context, work of planning and urban management to propose urban master planning base on integrating strategic planning values. Implementation and enforcement is a process which requires continuously consultation and participation to have on time adaption so as to archive optimal result of the whole planning process. 


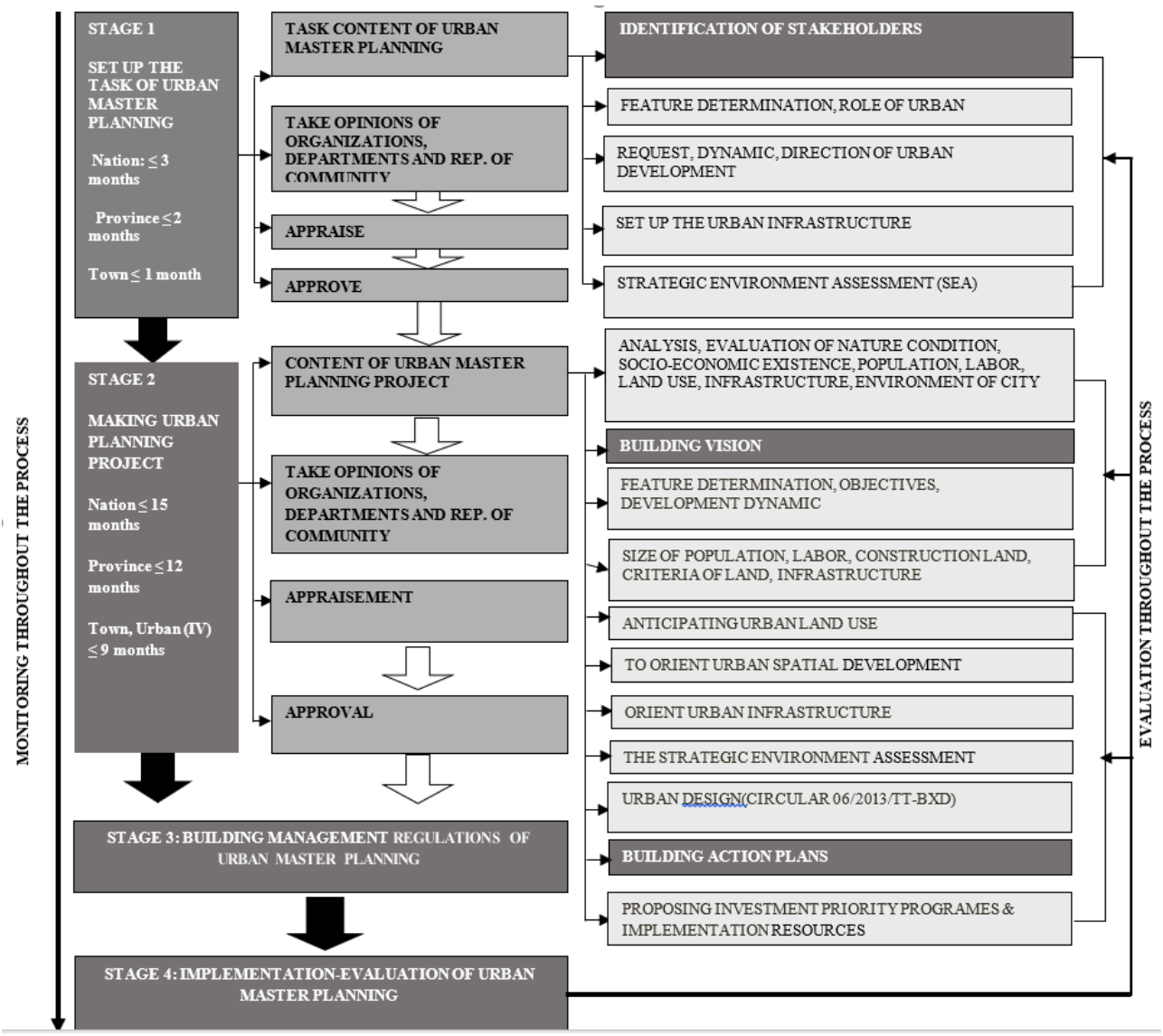

Fig. 7. Proposal of integrating values of strategic planning in the urban master planning process in Vietnam (Author, 2016).

\section{Discussions}

Because the research's scope is limited in urban master planning in Vietnam, on the basis result, further researches in other levels of planning such as zoning and detailed planning should be followed up to complete planning system in Vietnam.

Moreover, deal to the variety and complexity of related sectors; there are multiple paths of research to continuously apply strategic planning in the planning process in Vietnam. Particularly, in the theoretical term, it's necessary to deeper study in the fields which relate to urban planning like urban psychology, urban sociology, economy, politic, culture, etc.

On the other hand, urban planning is a process very much relate to local context. Therefore, in the eco-social condition of Vietnam, impacts from local elements like customs and habits, lifestyle in every city, area are also necessary to in-depth study.

Although further studies are needful, there are some requirements to successfully apply paper result in practice.

Enhance under-law documents related to stakeholders.

The urban and construction law was published recently in 2014 (other is in 2009) so it takes time to have accordant and accurate adjustment. Under-law documents such as decree 37/2010/NĐ-CP, 38/2010/NĐ-CP, 39/2010/are issued to guide urban planning activities, urban architecture, underground spaces, however, those instruments rarely mention about 
contents and method to cooperate between stakeholders, so it is necessary to explicitly identify role and tasks of participants.

Legalize the research result in the planning process.

New contents which are integrated to master planning in Vietnam should be legalized into legal documents, it will contribute to make urban planning distinct and feasible to implement with stakeholder's involvement.

Enhance strategic management thinking.

To successfully apply strategic tools in recent context, managers in different levels are required to have strategic think in making and implementing urban projects. Thematic conferences should be held frequently to wide-spread advance planning method and experience in both international and local cases. It is necessary to transfer this content expertise to people in planning and management field, especially the new generation who still sitting in university hall to continuously complete the research.

\section{Conclusions}

The paper has analyzed and systematized the Vietnamese urban master planning process, as well as strategic planning process in order to suggests integrating values of strategic planning, including flexible attributes of strategic planning in relevance to continuous operational process with participation and consultation of the stakeholders and contents of action planning mode, which are capable of adapting to changes in urban development process. Namely, integrating contents of building vision, action planning, monitoring, and evaluation of planning in carrying out and implementing of planning projects.

The paper is still limited on how to integrate values of strategic planning into Vietnam master planning process in the international integration. Detail information about how it turned out that the value integration happen will be analyzed and described in further papers.

\section{References}

1. Ma Van Phuc, Applying strategic planning approach into Vietnam urban planning process, PhD thesis of regional and urban planning (Hochiminh City University of Architecture, 2017)

2. Vietnam Government, Urban Planning Law number 30/2009/QH12 (2009)

3. Vietnam Government, Decree 42/2009/NĐ-CP about cities categorizing (2009)

4. Vietnam Government, Decree 37/2010/NĐ-CP about preparing, expertising urban planning practice (2010)

5. Do Phu Hung, A research of applying public participatory into Vietnam Urban Planning Projects, Doctoral Thesis (2004)

6. Civicus, Strategic planning http://www.civicus.org/view/media/Strategic\%20Planning. $\underline{\text { pdf }}(2011)$

7. UN-HABITAT, Citywide Strategic Planning: A step by step guide (Nairobi, 2010)

8. UN-HABITAT, Promoting Local Economic Development through Strategic Planning 15 (Nairobi, 2005)

9. UN-HABITAT, Planning sustainable cities, Earthscan, UK and USA (2009)

10. UN-HABITAT, Visioning - As participatory planning tool - Learning from Kosovo practices-Better cities for Kosovo (Nairobi, 2012)

11. UN-HABITAT, Green Growth City Development Strategy for Da Nang, UN-Habitat Office in Vietnam (2013) 
12. J. Van den Broeck, Urban trialogues: Visions projects Co-productions (UN-HABITAT, Nairobi, 2014)

13. Sustainable Development Institute of Sydney University of Technology, Guideline to create city development strategy in Vietnam (Hanoi, 2007)

14. N. Dang Son, Urban Planning Journal 12, 46 (2012)

15. N. Dang Son, Towards integrated multisectoral Investment 95, 051 (1998)

16. N. Dang Son, New Approach of Urban Planning and Management, Construction Publication (2006)

17. Vo Kim Cuong, Creating Development Strategy (CDS) applying for topics and local municipalities in Hochiminh City (Department of Science and Technology Hochiminh City)

18. N. Ngoc Hieu, Urban Planning Journal 05, 24 (2011)

19. N.Hong Thuc, Integrated strategic planning and capacity to apply in Vietnam Planning system, The Yearbook of Conference: Planning Law toward sustainable development and climate change adaptation (Hochiminh City, 2016)

20. Vietnam Institution of Architecture Urban and Rural Planning, Training material: Supporting cities to plan for the future, Module 1: Introduction to Urban Planning and Design, Mid-Career training for urban planner Ex-Sec 28 (Hanoi, 2009)

21. Ma Van Phuc, Planning and Construction Journal 75, 100 (2015)

22. Ma Van Phuc, Planning and Construction Journal 73, 82 (2015) 